\title{
Force Characterization and Optimization of the Bottom-Driven Type and Side-Driven Type Rotary Motion Electrostatic Actuator using FEM
}

\author{
P Mariam Md Ghazaly, Yuen Piaw Chin
}

\begin{abstract}
Three types of rotary motion electrostatic actuator were designed and analyzed using Finite Element Method (FEM) analysis. This paper will discuss the comparisons and detailed thrust force analysis of three types of the electrostatic actuator designs which are side-driven rotary electrostatic actuators, bottom-driven rotary electrostatic actuator (linear), and bottomdriven rotary electrostatic actuator (skewed). There are several similar parameters will be constant for the three types of rotary motion electrostatic actuator such as the number of pole of electrodes of rotor and stator, thickness of the rotor and stator, and air gap between the rotor and stator. The three designs that designed by the Ansys Maxwell $3 D$ and analyze the force generated by the designs. There are several parameters that are varying: (I) the actuator thickness;(ii) air gap between rotor and stator. In this paper, three types of designs for the rotary electrostatic actuator are discussed; i.e. (a) Bottom-driven (linear type), (b) bottom-driven (skewed type); and (c) Side-driven. From this research it was concluded that the bottom-driven (skewed type) actuator will produce the largest force compared to other actuator which is $5.95808 \mathrm{mN}$.
\end{abstract}

Keywords: Electrostatic actuator, FEM analysis, force optimization, rotary actuator.

\section{INTRODUCTION}

Development of Micro Electro Mechanical System (MEMS) is increasing rapidly throughout this year. MEMS consists of 3 main components which are microstructure, microsensor, and microactuator [1] or so called micromotor which can employ in microassembly, micropropulsion and microactuation [2]-[4]. Microactuator is the only one of the subset of the MEMS that converts energy to create motion such as rotary or linear motion. The microactuator can be applied in many fields such as the robotics, electronics, medicine, medical, biotechnology, communications and inertial sensing [5]-[8]. Furthermore, microactuator which the motion is rotary can be used in the platform for developing micropump such as fuel-delivery, drug-delivery, cooling, and vacuum application [9]-[12]. There are few types of microactuator which are electrostatic, electromagnetic and piezoelectric. The disadvantage of the electromagnetic is it will generate high heat [13], [14] whereas electrostatic type will produce low heat. Besides, piezoelectric type is a complex structure of actuator but

Revised Manuscript Received on September 14, 2019.

Mariam Md Ghazaly, Center for Robotic and Industrial Automation (CeRIA), Faculty of Electrical Engineering, Universiti Teknikal Malaysia, Melaka, Hang Tuah Jaya, 76100 Durian Tunggal, Melaka, Malaysia. (Email: mariam@utem.edu.my)

Yuen Piaw Chin, Faculty of Electrical Engineering, Universiti Teknika Malaysia, Melaka, Hang Tuah Jaya, 76100 Durian Tunggal, Melaka, Malaysia.. electrostatic type is a simple design and easy to maintain [15].

In the robotic field, the microactutor is needed due to the weight of the actuator must be as light as possible. The main challenges in the insect robots is related to the actuator used which must have the criteria such as providing the sufficient power for autonomous flight with wide variations in driving voltages and currents [5]. In additions, the microactuator can be utilized in the electronic field such as improving the performance of the hard-disk drives (HDD). This microactuator will act as the secondary drives in HDD by reducing the skew angle during the disk operation [6]. Furthermore, the microactuator also can be used in the surgery in medical field [16]. The microactuator is using in the micro-mirror devices of the laser phononicrosurgery which acts as the manipulator of the laser source. It allows the micro-mirror operate in a high precision and low power consumption condition [7]. These factors have contributed to the interest in understanding the microactuator would be start of it.

\section{METHODOLOGY}

\section{A Basic Electrostatic Actuator}

Electrostatic actuator is a device that converts energy to create motion which is based on the attractive and repulsive force of electric charge. Basically electrostatic actuator has two types of motion which are linear motion and rotary motion. For rotary motion there are two types method to drive the actuator such as side-driven and bottom-driven whereas the linear motion which has comb-driven. As in shown Fig. 1, the side-driven's rotor is mounted inside the stator whereas the bottom-driven's rotor is above the stator. Besides, the comb-drive linear electrostatic actuator's rotor or so called mover is in and out of the stator [17].

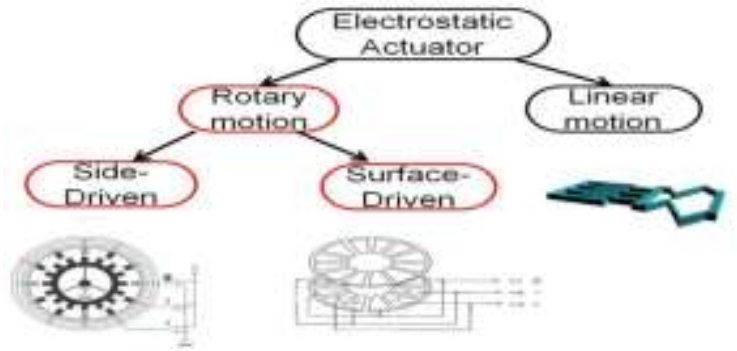

Fig. 1.Chart about the sub-element of electrostatic actuator [6], [18], [19].

Published By

Blue Eyes Intelligence Engineering

\& Sciences Publication 


\section{FORCE CHARACTERIZATION AND OPTIMIZATION OF THE BOTTOM-DRIVEN TYPE AND SIDE-DRIVEN TYPE ROTARY MOTION ELECTROSTATIC ACTUATOR USING FEM}

\section{B Basic Principle}

From Fig. 2, the mover is allocated above the stator, where the stator is grounded. The mover is fixed with a distance, $d$ from the stator as shown in (1). When voltage is applied to the mover, the mover will align with the stator, thus motion is generated.

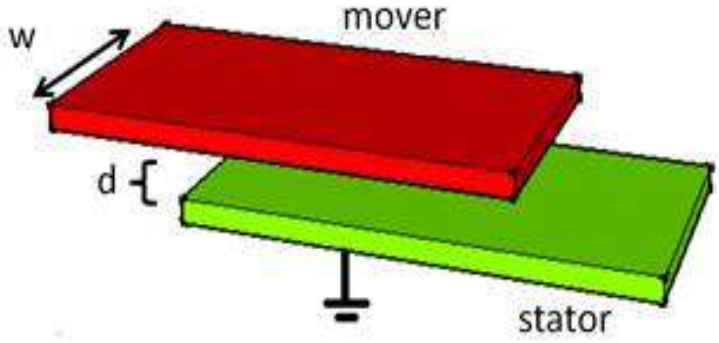

Fig. 2.Basic linear electrostatic microactuator.

In (1) shows the equation that is related to the electrostatic force. The equation shows all the parameter that will affect the performance of force of the microactuator $(\mathrm{F})$ such as the number of electrodes activate per phase (n), permittivity of material ( $\varepsilon$ ), width of electrode(w), distance between the stator and rotor(d), and the voltage supply (V). The force of the microactuator is given in (1).

$$
F=n \frac{1}{2} \varepsilon \frac{w}{d} V^{2}
$$

\section{Working Principle of Rotary Electrostatic Actuator}

The applied voltage to the rotary electrostatic microactuator is a 3-phase system. Fig. 3 shows the principle of motion when the 1 st phase of voltage activated at one pair of poles of the stator and it will produce a voltage different with the grounded rotor. Therefore, the voltage difference will produce the electrostatic force and this force will make the pole of the rotor rotate to align with the pole of the stator. The same operation will apply to the 2nd and 3rd phase of the voltage activation.

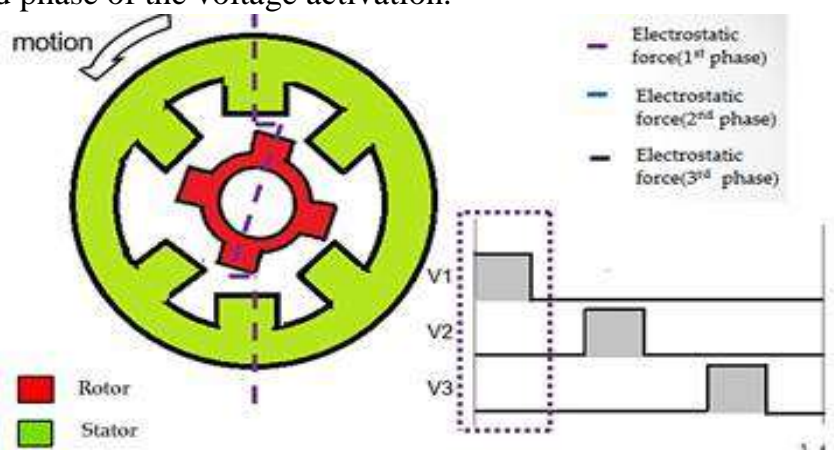

(a)Voltage is applied to electrostatic actuator

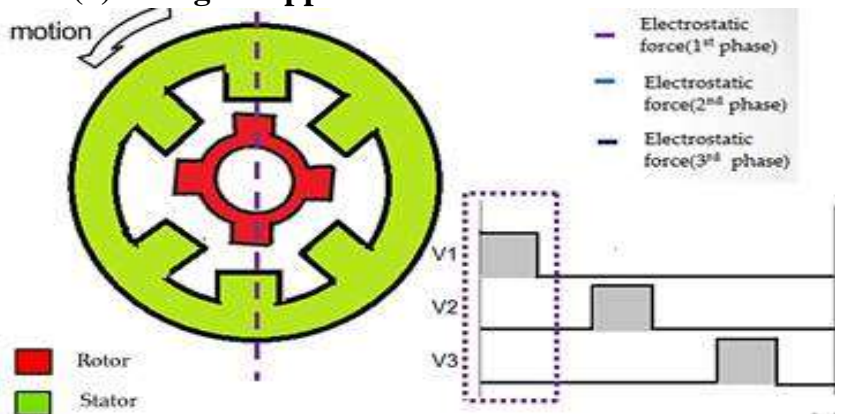

(b)The rotor aligns with the stator pair with voltage activation
Fig. 3.Working principle of the rotary electrostatic actuator

\section{Initial Condition for the Three Designs}

The parameters for designing of the 3 types of the electrostatic actuators are from (1) and different values of parameters may give different results if as shown in Table I.

Table- I: The initial condition for the three designs of electrostatic actuator

\begin{tabular}{|c|c|c|c|c|c|c|}
\hline & \multicolumn{6}{|c|}{ Parameter } \\
\hline & $\begin{array}{c}\text { Thickn } \\
\text { ess } \\
(\mathbf{m m})\end{array}$ & $\begin{array}{c}\text { Size } \\
(\mathbf{m m} \\
)\end{array}$ & $\begin{array}{c}\text { Air } \\
\text { Gap } \\
(\mathbf{m m} \\
)\end{array}$ & $\begin{array}{c}\text { No. of } \\
\text { Pole } \\
\text { (Rotor) }\end{array}$ & $\begin{array}{c}\text { No. of } \\
\text { Pole } \\
\text { (Stator) }\end{array}$ & $\begin{array}{c}\text { Angle } \\
\text { Skewed }\end{array}$ \\
\hline Design 1 & 50 & 700 & 2 & 16 & 12 & $0^{\circ}$ \\
\hline Design 2 & 100 & 700 & 2 & 16 & 12 & $0^{\circ}$ \\
\hline Design 3 & 100 & 700 & 2 & 16 & 12 & $0.9^{\circ}$ \\
\hline
\end{tabular}

E Initial Design of Electrostatic Actuator Using Ansys Maxwell 3D

In this research, 3 types of rotary electrostatic actuator were designed which are (a) side-driven electrostatic actuator, (b) bottom-driven electrostatic actuator (linear), and (c) bottom-driven electrostatic actuator (skewed). Fig. 4-6 show the 3 types of the designs, there are 16 electrodes of rotors and 12 electrodes of stators. Besides, the air gap between the rotor and the stator is $2 \mu \mathrm{m}$. The size of the actuators is $700 \mu \mathrm{m}$ in radius and the thickness for the rotor and stator are $50 \mu \mathrm{m}$ in the Fig. 4 , but $100 \mu \mathrm{m}$ for the design of Fig. 5 and 6. The zoom view in the Fig. 6 shows the skewed angle, $\theta$ equal to $0.9^{\circ}$ [20].

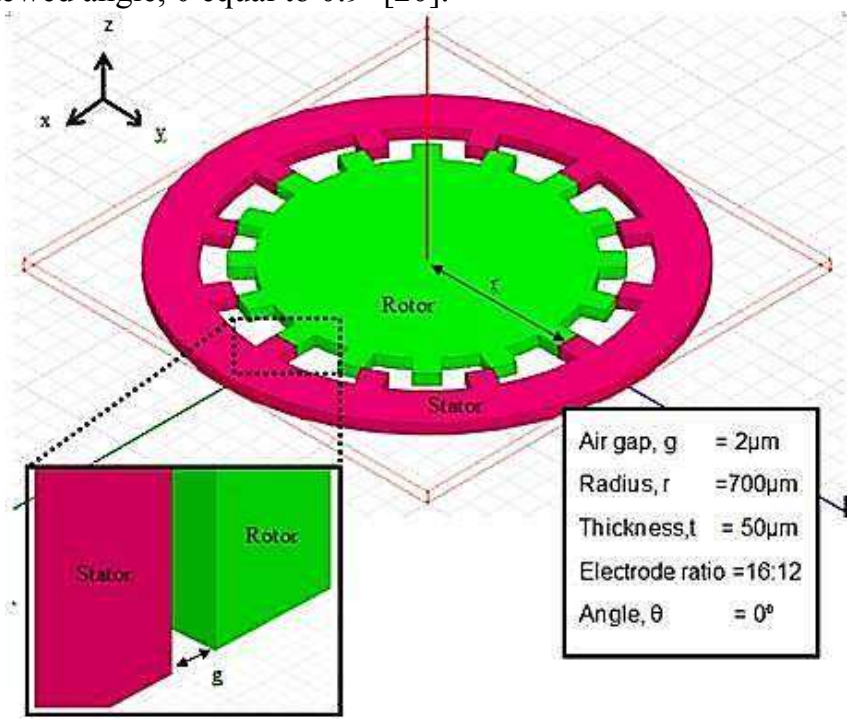

Fig. 4.3D view of the Design 1 (Side-Driven) with initial dimension using Ansys Maxwell 3D.

Published By: 


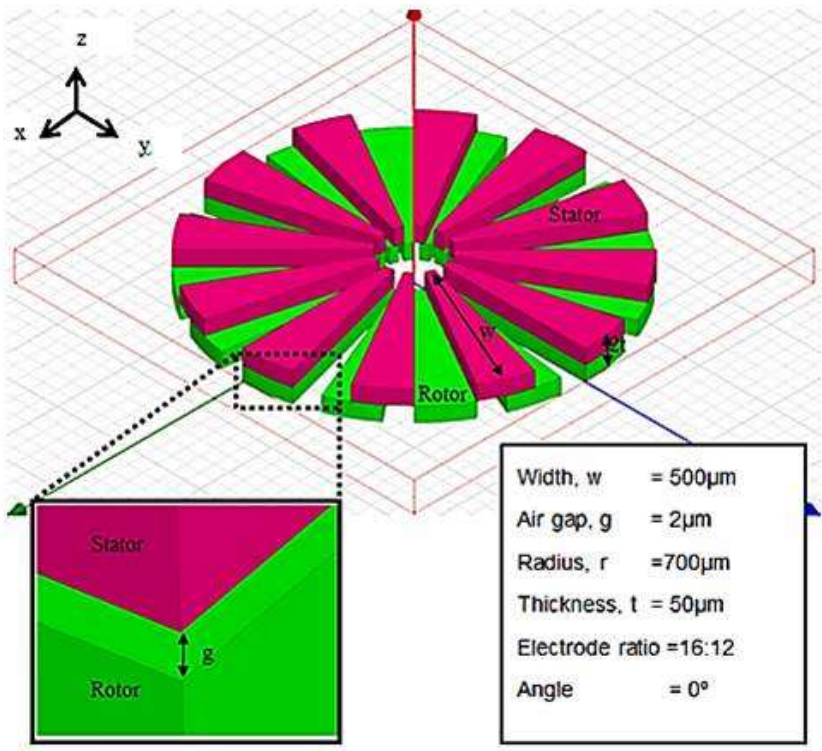

Fig. 5.3D view of the Design 2 (Bottom-Driven (Linear)) with initial dimension using Ansys Maxwell 3D.

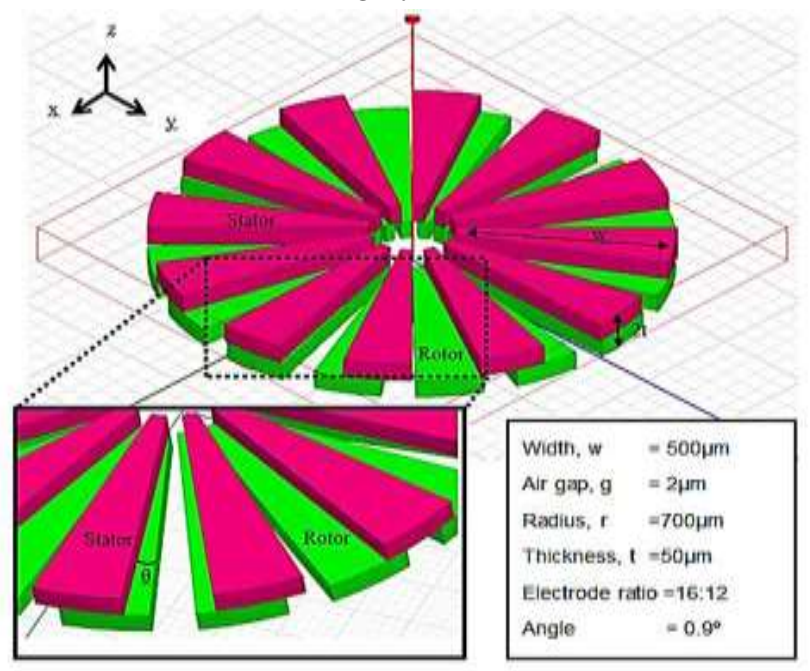

Fig. 6.3D view of the Design 3 (Bottom-Driven (Skewed)) with initial dimension using Ansys Maxwell $3 D$.

\section{F Comparison between Design 2 and Design 3}

Fig. 7 and 8 are the zoom view for both bottom-driven (linear) and bottom-driven (skewed) respectively. The dotted circles in the Fig. 7 and 8 show the different that very difficult to notice it which is the angle skewed of the bottom-driven (linear) is $0^{\circ}$ whereas the angle skewed is $0.9^{\circ}$.

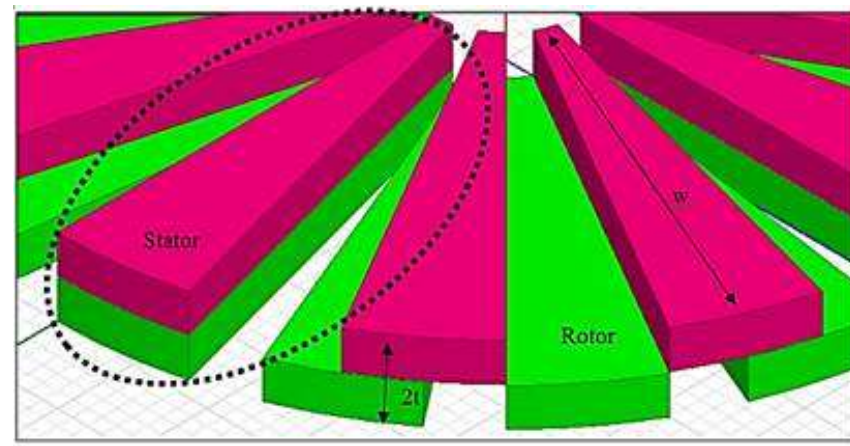

Fig. 7.Zoom view of the Design 2(Bottom-Driven (Linear)) electrostatic actuator.

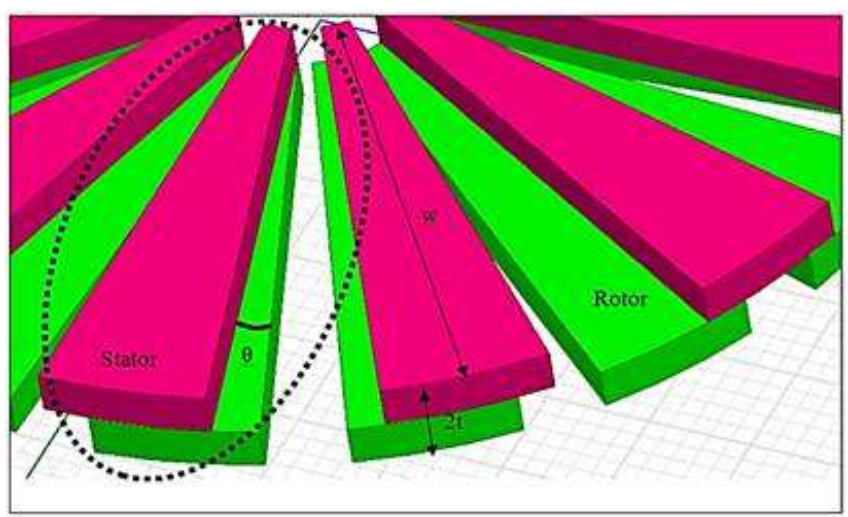

Fig. 8.Zoom view of the Design 3( Bottom-Driven (Skewed)) electrostatic actuator, $\theta=0.9$.

\section{RESULTS AND DISCUSSION}

The type of the analysis used in this research is Finite Element Analysis (FEA) or Finite Element Method (FEM). The Finite Element Method is a numerical method for solving problems of engineering and mathematical physics and this analysis method is very useful for problem with complicated geometries, loadings, and material properties. The Finite Element Method was used to analysis and optimizes the rotary electrostatic designed parameters. Two types of parameters were varied which were the thickness and the air gap of the electrostatic actuators for the three types of designs.

\section{A Effect of Varying Electrode Thickness}

In this section, the thickness of actuator was varied from $10 \mathrm{~mm}$ to $50 \mathrm{~mm}$ with the interval of $10 \mathrm{~mm}$ whereas other parameters are constant in such a way $700 \mathrm{~mm}$ of size, $2 \mathrm{~mm}$ of air gap, and teeth ratio of 16:12. Fig. 9 was the drawing which done by using Ansys Maxwell 3D which one the example for the method to varying the thickness of the actuator.

\section{B Design 1 (Side-Driven)}

As shown in Fig. 10, the analysis was done with varying the thickness of the electrostatic actuator with $10 \mathrm{~mm}$, $20 \mathrm{~mm}, 30 \mathrm{~mm}, 40 \mathrm{~mm}$ and $50 \mathrm{~mm}$ against with $0 \mathrm{~V}$ to $100 \mathrm{~V}$ with the interval of $10 \mathrm{~V}$. The side-driven electrostatic actuator with the thickness of $50 \mathrm{~mm}$ created the highest force which was $23.05942 \mathrm{mN}$ compared to others. However, there were different between the data collected as shown in Table II and Fig. 10. According to the Maxwell theory, the thicker the actuator, the greater the force will be created. This is because area of intersection is big due to the increase in the thickness of the actuator. In the other words, the actuator with the thickness of $40 \mathrm{~mm}$ should create higher force than the actuator with $30 \mathrm{~mm}$ but the data collected shows in another way. The reason that this situation happened was due to the passes of the $40 \mathrm{~mm}$ of voltage $100 \mathrm{~V}$ has 5 passes or iteration or the energy error was $3.147 \%$ whereas for the actuator with thickness $30 \mathrm{~mm}$ was 4 passes and $3.3545 \%$ energy error. All thickness of

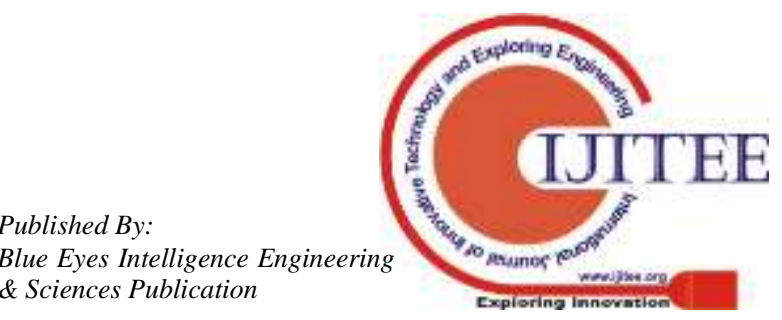




\section{FORCE CHARACTERIZATION AND OPTIMIZATION OF THE BOTTOM-DRIVEN TYPE AND SIDE-DRIVEN TYPE ROTARY MOTION ELECTROSTATIC ACTUATOR USING FEM}

actuator has 5 passes except $20 \mathrm{~mm}$ and $30 \mathrm{~mm}$ thickness as shown in the Table II. The energy error (\%) was set maximum $5 \%$ in Ansys Maxwell 3D.

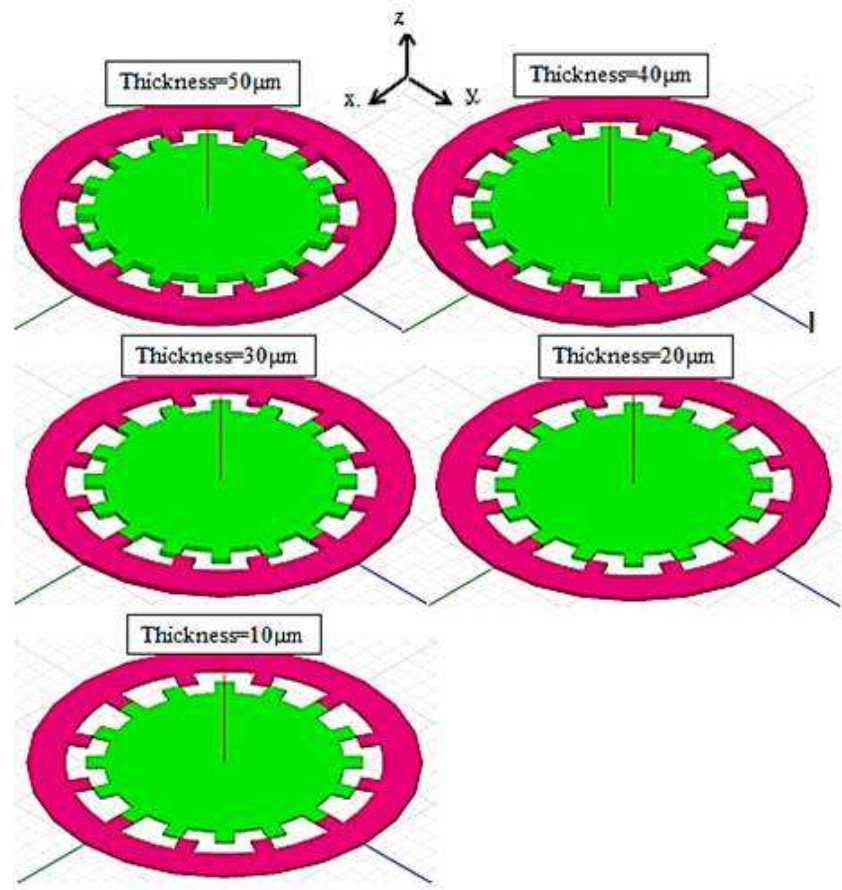

Fig. 9.Varying of the thickness of the Design 1(SideDriven) actuator.

Table- II: Comparison of the passes and energy error for different thickness

\begin{tabular}{|c|c|c|}
\hline $\begin{array}{c}\text { Thickness (mm) } \\
\text { for 100V }\end{array}$ & $\begin{array}{c}\text { Pas } \\
\text { ses }\end{array}$ & $\begin{array}{c}\text { Energy Error } \\
(\boldsymbol{\%})\end{array}$ \\
\hline 10 & 5 & 4.0922 \\
\hline 20 & 4 & 2.9021 \\
\hline 30 & 4 & 3.3545 \\
\hline 40 & 5 & 3.147 \\
\hline 50 & 5 & 4.7528 \\
\hline
\end{tabular}

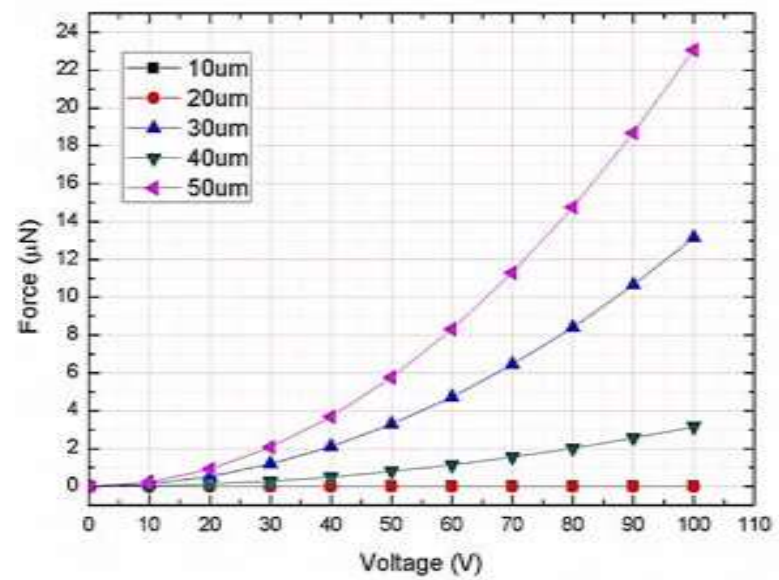

Fig. 10.Graph of the data collected by varying the thickness of the Design 1(Side-Driven) electrostatic actuator.

\section{Design 2 (Bottom-Driven (Linear))}

From Fig. 11, the data shows that by varying the thickness of the bottom-driven (linear) electrostatic actuator, there is nothing significant changes in the force produced. This is because that the thickness increase does not help in increase of the intersection of surface area. As explained of the equation of Maxwell, only the activation surface will affect the force created and the highest force created from Design 2 actuator was $5.1108 \mathrm{mN}$.

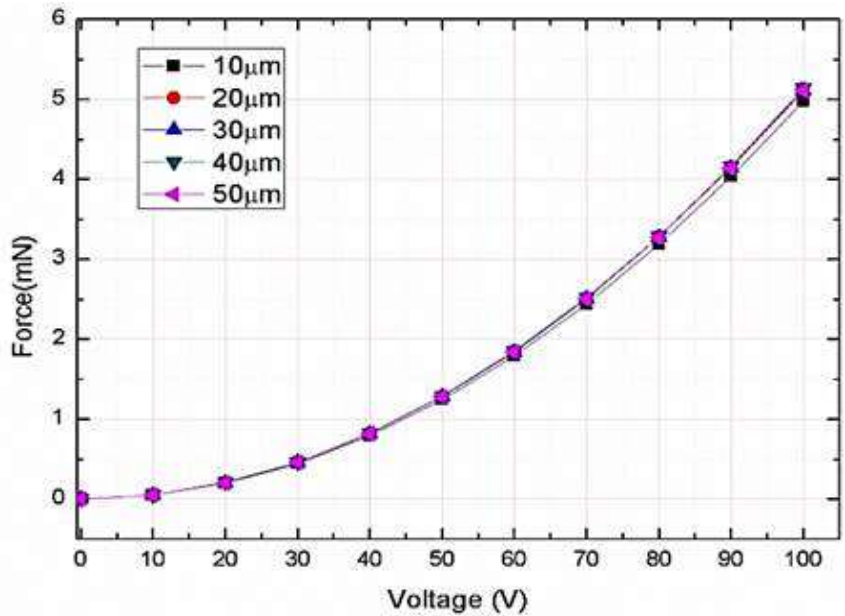

Fig. 11.Graph of the data collected by varying the thickness of the bottom-driven (linear) electrostatic actuator.

\section{Design 3 (Bottom-Driven (Skewed))}

From Fig. 12, the data show that by varying the thickness of the bottom-driven (skewed) electrostatic actuator, there is nothing big changes in the force produced. This is because that the thickness increase does not help in increase of the intersection of surface area. As explained of the equation of Maxwell, only the activation surface affects the force produced. This is alike with the bottom-driven (linear) electrostatic actuator as shown before. The highest force created is $5.95808 \mathrm{mN}$.

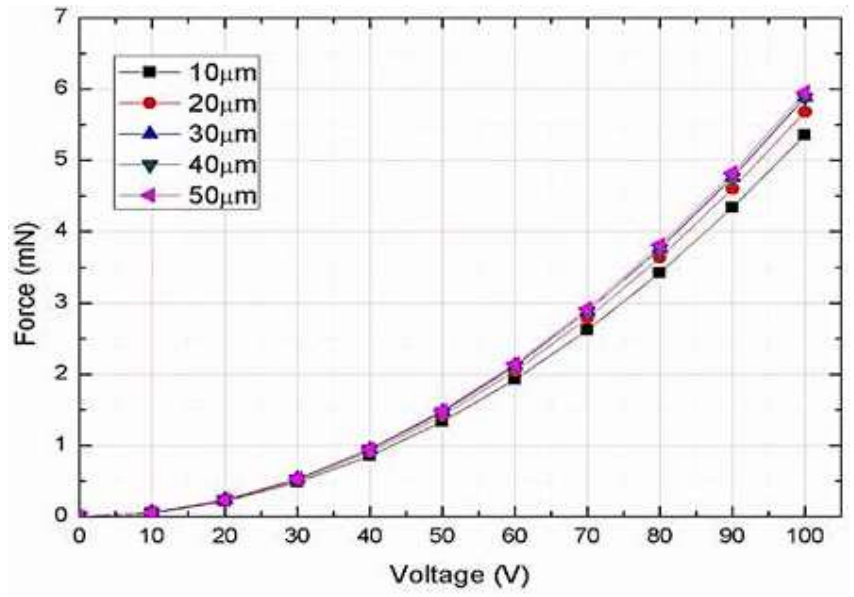

Fig. 12.Graph of the data collected by varying the thickness of the bottom-driven (skewed) electrostatic actuator.

\section{E Effect of Varying Air Gap between Stator and Rotor}

In this section, the gap of the actuator was varied from $2 \mu \mathrm{m}$ to $5 \mu \mathrm{m}$ with the interval of $1 \mu \mathrm{m}$ whereas other parameters were constant in such a way of $50 \mu \mathrm{m}$ of thickness, $700 \mu \mathrm{m}$ of size, and teeth ratio of 16:12. Fig. 13 was the drawing done by using Ansys Maxwell 3D which one the example for the method to varying the air gap of the actuator. 

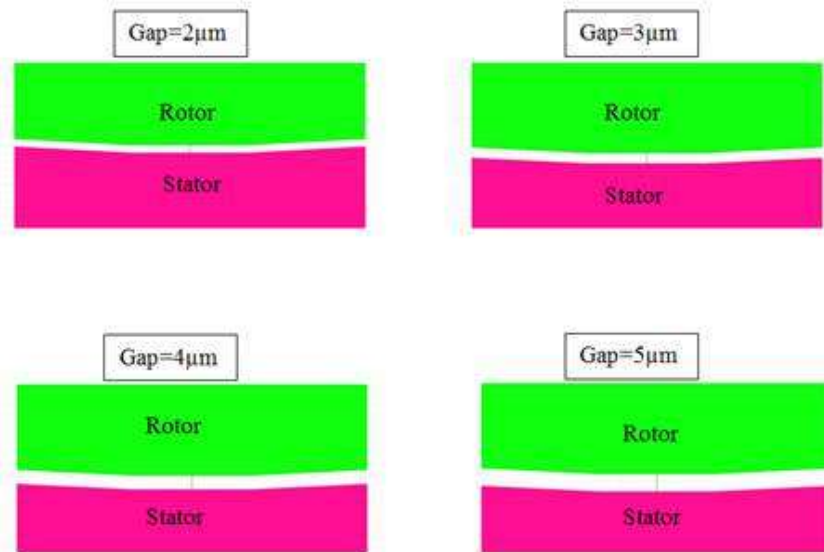

Fig. 13.Varying of the gap of the Design 1 actuator.

\section{F Design 1 (Side-Driven)}

The gap between rotor and the stator according to the equation of Maxwell affects the force produced by the electrostatic actuator. As the gap between stator and rotor decreases, the force created is greater as shown in Fig. 14. From Fig. 14, the electrostatic actuator with $2 \mathrm{~mm}$ gap between stator and rotor produced the highest force compared to $3 \mathrm{~mm}, 4 \mathrm{~mm}$, and $5 \mathrm{~mm}$. This is because as the gap become smaller, the attractive force from the stator is bigger when the voltage is applied. On the other hand, as the gap between the stator and rotor become bigger, the attractive force will become weaker and this make the electrode at rotor rotates slower to align with the electrode of the stator compared to the electrostatic actuator with smaller gap.

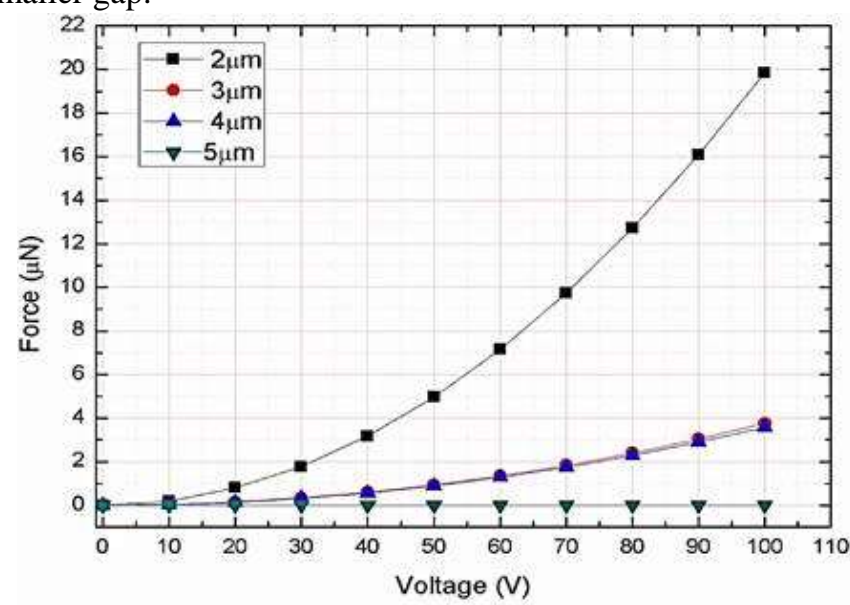

Fig. 14.Graph of the data collected by varying the gap between stator and rotor of the side-driven electrostatic actuator.

\section{G Design 2 (Bottom-Driven (Linear))}

Fig. 15 shows the FEM analysis on Design 2 by varying the gap between the stator and rotor of the electrostatic actuator from $2 \mathrm{~mm}$ to $5 \mathrm{~mm}$ with the interval of $1 \mathrm{~mm}$. In addition, Fig. 15 shows the smaller the gap, the higher the force is created which is $5.11082 \mathrm{mN}$. In other words, the force produced by bottom-driven (linear) electrostatic actuator with the gap of $2 \mathrm{~mm}$ is the highest compared to the other electrostatic actuator with the gap of $3 \mathrm{~mm}$ to $5 \mathrm{~mm}$.

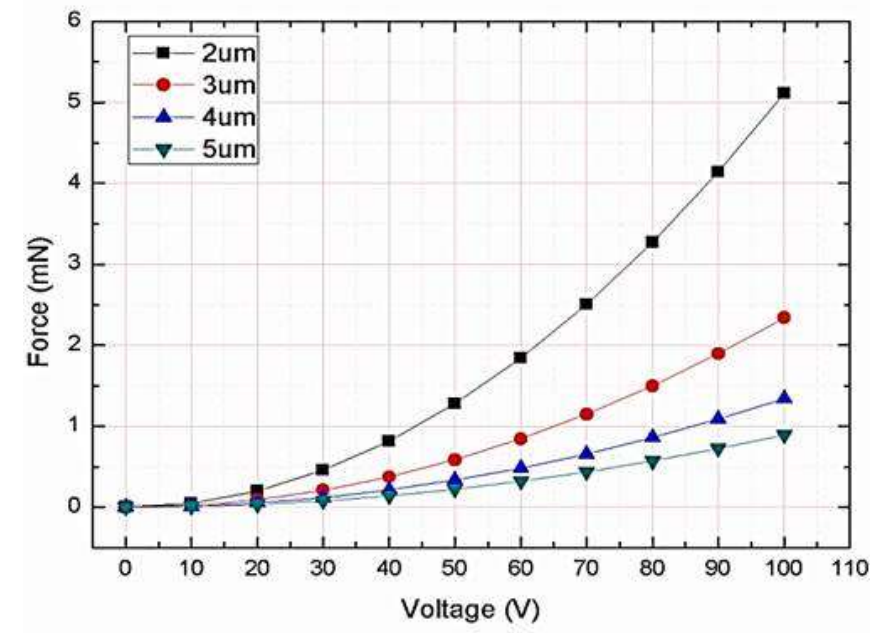

Fig. 15.Graph of the data collected by varying the gap between stator and rotor of the bottom-driven (linear) electrostatic actuator.

\section{H Design 3 (Bottom-Driven (Skewed))}

Fig. 16 shows the FEM analysis in this section by varying the gap between the stator and rotor of the bottom-driven (skewed) electrostatic actuator from $2 \mathrm{~mm}$ to $5 \mathrm{~mm}$ with the interval of $1 \mathrm{~mm}$. The results show that the smaller the gap, the higher the force is created which is $5.95808 \mathrm{mN}$. In other words, the force produced by bottom-driven (skewed) electrostatic actuator with the gap of $2 \mathrm{~mm}$ is the highest compared to the other electrostatic actuator with the gap of $3 \mathrm{~mm}$ to $5 \mathrm{~mm}$.

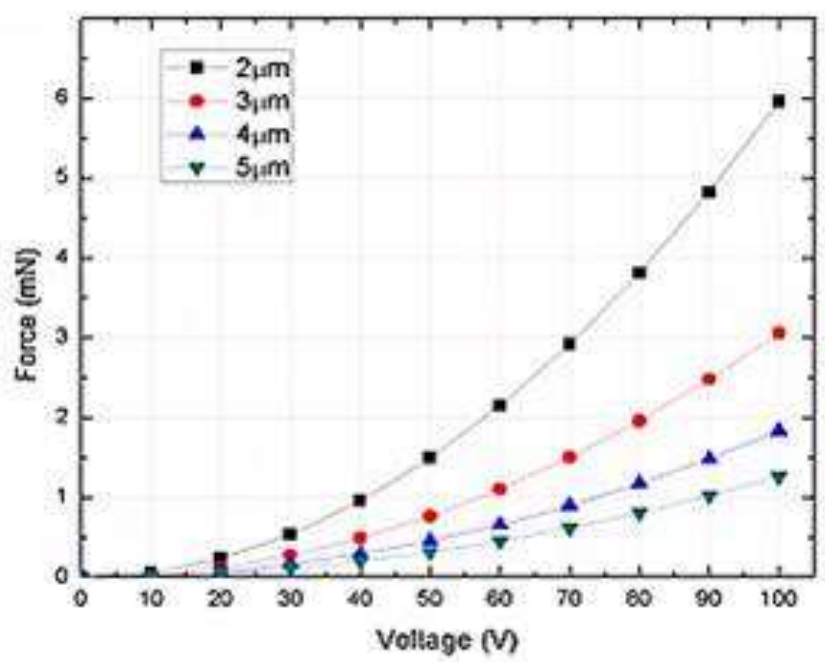

Fig. 16.Graph of the data collected by varying the gap between stator and rotor of the bottom-driven (skewed) electrostatic actuator.

\section{CONCLUSION}

In conclusion, Table III shows the overall highest force produced is the bottom-driven (skewed) with $5.95808 \mathrm{mN}$. Then, follow by the bottom-driven (linear) with $5.1108 \mathrm{mN}$ and the lowest force product actuator is the side-driven with $23.05942 \mathrm{mN}$. These is due to the overlap surface of the bottom-driven (skewed) is larger than other 2 designs. 

TYPE ROTARY MOTION ELECTROSTATIC ACTUATOR USING FEM

Bottom-driven (skewed) with the dimensions of $50 \mathrm{~mm}$ thickness, $2 \mathrm{~mm}$ gap, teeth ratio of $16: 12$ and $700 \mathrm{~mm}$ of size produced the highest force which is $5.95808 \mathrm{mN}$ according to FEM analysis.

Table- III: Comparison of the passes and energy error for different thickness

\begin{tabular}{|c|l|l|l|}
\hline Parameter & \multicolumn{3}{|l|}{ Designs } \\
\hline & $\mathbf{1}$ & $\mathbf{2}$ & $\mathbf{3}$ \\
\hline $\begin{array}{c}\text { Thickness } \\
(\mathrm{mm})\end{array}$ & 50 & 500 & 500 \\
\hline Size $(\mathrm{mm})$ & 700 & 700 & 700 \\
\hline Gap $(\mathrm{mm})$ & 2 & 2 & 2 \\
\hline R:S & $16: 12$ & $16: 12$ & $16: 12$ \\
\hline Force(N) & $23.05942 \mathrm{~m}$ & $5.43046 \mathrm{~m}$ & $5.95808 \mathrm{~m}$ \\
\hline
\end{tabular}

\section{ACKNOWLEDGMENT}

The authors wish to express their gratitude to Motion Control Research Laboratory (MCon Lab), Center for Robotics and Industrial Automation (CeRIA) and Universiti Teknikal Malaysia Melaka (UTeM) for supporting the research and publication. This research and its publication are supported by Ministry of Higher Education Malaysia (MOHE) under the Fundamental Research Grant Scheme (FRGS) no. FRGS/2018/FKE-CERIA/F00353, Center for Robotics and Industrial Automation (CeRIA) and Center for Research and Innovation Management (CRIM).

\section{REFERENCES}

1. M. M. Ghazaly, A. C. Tan, A. C. Amran, and K. Sato, "Force characterization of a rotary motion based on Finite Element Method (FEM) analysis," Applied Mechanics and Material, 761, 2015, pp. 233-237.

2. S. Fatikow, A. Falzullin, and J. Seyfried, "Planning of a microassembly task in a flexible microrobot cell," IEEE International Conference on Robotics and Automation, 2000, pp. 1121-1126.

3. R. Yeh, S. Hollar, and K. S. J. Pister, "Design of lowpower silicon articulated microrobots," J. Micromechatronics, 1(3), 2002, pp. 191-203.

4. R. Yeh, E. J. J. Kruglick, and K. S. J. Pister, "Surfacemicromachined components for articulated microrobots," J. Microelecrtromech. Syst., 5(1), 1996, pp. 10-17.

5. M. Karpelson and R. J. Wood, "A review of actuation and power electronics options for flapping-wing robotic insects," IEEE Int. Conf. Robot. Autom., 2008, pp. 779786.

6. E. Sarajlic, C. Yamahata, M. Cordero, and H. Fujita, "Three-phase electrostatic rotary stepper micromotor with a flexural pivot bearing," J. Microelectromechanical Syst., 19(2), 2010, pp. 338-349.

7. E. Pengwang, K. Rabenorosoa, M. Rakotondrabe, and N. Andreff, "Characterization and micro-assembly of electrostatic actuators for 3-DOF micromanipulators in laser phonomicrosurgery," IEEE/ASME 10th Int. Conf. Mechatron. Embed. Syst. Appl., 2014, pp.1-6.

8. T. Niino, T. Higuchi, and S. Egawa, "AC dual excitation multiphase electrostatic drive," Journal of the Robotics Society of Japan, 15(1), 1997, pp. 97-102.

9. D. J. Laser and J. G. Santiago, "A review of micropumps," J. Micromech. Microeng., 14(6), 2004, pp. R35-R64.

10. T. Weisener, G. Vogele, M. Widmann, C. Bark, R. D. Schraft, A. Bertholds, and A. Braunschweiler, "Development and fabrication of a rotary micropump and its industrial and medical application," Proceedings
Volume 2882-Micromachined Devices and Components II, 1996, pp. 218-225.

11. C. H. Ahn and M. G. Allen, "Fluid micropumps based on rotary magnetic actuators," Proceedings IEEE Micro Electro Mechanical Systems, 1995, pp. 408-412.

12. B. Mladen, J. M. Jack, P. G. Andrew, and S. Schultz, "Electromagnetic micromotor for microfluidics application," Appl. Phys. Lett., 79(9), 2001, pp. 1399 1401.

13. D. M. Taylor and P. E. Secker, Industrial Electrostatics: Fundamentals and Measurements. England: Research Studies Press, 1994.

14. Y. Zhu, J. Shi, W. Shen, X. Dong, J. Feng, and M. Ruan, "Stimuli-responsive controlled drug release from a hollow mesoporous silican sphere/polyelectrolyte multilayer coreshell structure," Angew. Chem., 117(32), 2005, pp. 5213-5217.

15. M. M. Ghazaly, T. K. Lim, Y. P. Chin, and K Sato, "Force optimization of an force artificial mucle actuated underwater probe system using linear motion electrostatic motor," Jurnal Teknologi, 74(9), 2015, pp. 191-196.

16. D. Polla, A. Erdman, D. Peichel, R. Rizq, Y. Gao, and D. Markus, "Precision micromotor for surgery," IEEE 1st Annual International IEEE-EMBS Special Topic Conference on Microtechnologies in Medicine and Biology, 2000, pp. 180-183.

17. R. X. Gao, J. Fang, B. Rao, and R. O. Warrington, "Miniaturized surface-driven electrostatic actuators design and performance evaluation," IEEE/ASME Trans. Mechatronics., 2(1), 1997, pp. 1-7.

18. G. Guisbiers and M. Wautelet, "Materials selection for micro-electromechanical systems," Mater. Des., 28(1), 2007, pp. 246-248.

19. V. T. Srikar and S. M. Spearing, "Materials selection for microfabricated electrostatic actuators," Sensors Actuators A Phys., 102(3), 2003, pp. 279-285.

20. T. Hosobata, A. Yamamoto, and T. Higuchi, "An electrostatic induction motor utilizing electrical resonance for torque enhancement," Sensors Actuators A Phys., 173(1), 2012, pp. 180-189

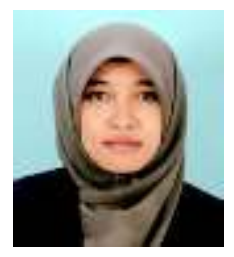

\section{AUTHORS PROFILE}

Mariam Md Ghazaly is currently an Associate Professor at the Department of Mechatronic Engineering, Faculty of Electrical Engineering, Universiti Teknikal Malaysia Melaka (UTeM), Malaysia. She received her B. Eng. \& M. Eng. in the field of Electrical \& Mechatronic Engineering from Universiti Teknologi Malaysia, Malaysia in 2003 \& 2005. In 2009 \& 2012, she received her M. Eng. \& Doctor of Eng. from Tokyo Institute of Technology, Japan in the field of Mechano-Micro Engineering (Precision Engineering). Her research interest is in the field of Actuator Design, MEMS, Precision Engineering \& Non-linear Control. 